American Journal of Pharmaceutical Education 2019; 83 (5) Article 6688.

\title{
RESEARCH
}

\section{A Framework Model for a Contextualized and Integrated Warfarin Therapy Case in a Master of Pharmacy Program}

\author{
Suzanne Fergus, PhD, MA, Amandeep Birdi, MPharm, Farakh Riaz, MPharm \\ School of Life and Medical Sciences, University of Hertfordshire, Hertfordshire, United Kingdom \\ Submitted August 1, 2017; accepted March 7, 2018; published June 2019.
}

Objective. To develop and integrate a case study on warfarin into a clinical pharmacy workshop.

Methods. A framework model was designed and used to create a case study on warfarin therapy. The case study was implemented in a third-year Master of Pharmacy course. Student feedback was obtained using an online questionnaire and two focus groups.

Results. All students agreed that the case study successfully integrated the science of warfarin and concepts of pharmacy practice. The majority of students (94\%) agreed that this approach helped them to understand the science of warfarin more than a traditional lecture would have. Students felt the time allocated to the workshop was too short.

Conclusion. An integrated case study provides a learning environment that emphasizes the contextualization of chemistry and pharmacology into a clinical pharmacy setting.

Keywords: contextualization, integrated learning, case studies, warfarin therapy

\section{INTRODUCTION}

Patient safety lies at the core of the pharmacy profession. Pharmacists have a central role in maintaining the health, safety, and wellbeing of patients. Because of the narrow therapeutic window of warfarin, pharmacists play a key role in the management of patients for whom the drug is prescribed. The risks of adverse drug reactions that can occur with warfarin are high because of the numerous potential food and drug interactions. ${ }^{1}$ Thus, it is vital for pharmacists to have and be able to use their scientific knowledge in this area. A key focus of pharmacy education is to integrate scientific principles into the curriculum that underpin effective pharmacy practice. This article outlines a framework developed and then used to design an integrated clinical case study for warfarin treatment. The case study was used to test students' comprehension of the material and ability to apply scientific principles in pharmacy practice.

The United Kingdom's General Pharmaceutical Council (GPhC) has emphasized in their educational standards for accredited Master of Pharmacy (MPharm) degree programs that "sound science is the basis of effective pharmacy." Integration is also emphasized by the Center for Advancement of Pharmacy Education (CAPE) $)^{3}$ and

Corresponding Author: Suzanne Fergus, Department of Pharmacy, Pharmacology and Postgraduate Medicine School of Life and Medical Sciences, University of Hertfordshire, Hatfield, AL10 9AB United Kingdom. Tel: +44(0)1707 286591. E-mail: s.fergus@herts.ac.uk the Accreditation Council for Pharmacy Education (ACPE) standards for Doctor of Pharmacy (PharmD) degree programs with assessment outcomes that "reflect mastery of the sciences and their integration in pharmacy practice." "This discipline integration approach in pharmacy education has been highlighted as one of the leading strategies in teaching pharmacy practice. ${ }^{5}$

There is a clear shift in pharmacy education from placing the responsibility solely on students to make connections that link different disciplines to implementing curriculum design that facilitates an integrative approach to learning. Curricular integration in pharmacy education includes horizontal integration crossing discipline boundaries and vertical integration connecting across time and between theory and practice. ${ }^{6}$ This includes Harden's ladder of integration where multidisciplinary (separate disciplines focusing on a common theme), interdisciplinary (disciplines developing a shared understanding of a topic), and transdisciplinary (disciplinary distinctions not evident) form part of a gradated scale for curriculum integration. ${ }^{7}$ There is no single preferred integration strategy when dealing with a complex curriculum.

The use of real-life applications to introduce or contextualize the study of a scientific concept is an example of vertical integration and is especially important in pharmacy education in order to translate safe and effective practice from the classroom to the clinical setting. Previous research has described contrasting methods of contextualization, some of which have incorporated simulated or virtual patients. For example, the Pharmville' 


\section{American Journal of Pharmaceutical Education 2019; 83 (5) Article 6688.}

project developed a fictional community of people to augment learning in an undergraduate pharmacy program. Through this virtual experience, students could explicitly see the link between the chemistry of drugs and the people who actually used them. ${ }^{8}$ A three-week course that integrated relevant pharmaceutical and clinical sciences through a combination of lectures, case studies, and other teaching methods demonstrated high pass rates on assessments. Furthermore, students found the integration "very or extremely" relevant in terms of application of basic sciences in clinical knowledge compared to the traditional approach to learning. ${ }^{9}$ Other successful integrated approaches to teaching clinical pharmacy include team-based learning a task-based learning exercise involving a simulated drug discovery activity and team-based case study exercises. ${ }^{10-12}$ A flipped classroom model using vodcasts (video podcasts) prior to in-class discussions of interactive case studies of patients with end-stage renal disease resulted in significant improvement in students' examination performance. ${ }^{13}$ Case-based integration in a medicinal chemistry and pharmacotherapy course facilitated more active participation from students in the learning and evaluation process. ${ }^{14}$ Not surprisingly, the case study approach features strongly in the examples of integration as it provides scenarios that students are likely to encounter in professional practice. Students are challenged to explore their existing preconceptions and modify them to accommodate the realities of the case studies. The scenarios presented tend to be rich in contextual details, which requires students to apply material with which they are already somewhat familiar. ${ }^{15}$

The positive impact of using case studies is well documented. An extensive review from Bennett and colleagues of 17 experimental studies undertaken in eight different countries on the effects of context-based approaches, including case studies, to science teaching in secondary schools found that context-based approaches resulted in improved attitudes to science among students because the science was made relevant to their lives and possible future careers. ${ }^{16}$ Currie and colleagues reported that small, group workshops requiring students to work through integrated medicinal chemistry cases improved student attitudes towards science as the cases studies allowed them to avoid the tedious task of simply memorizing structures and drug interactions. ${ }^{17}$

Despite the effective outcomes and implementation of contextualized case studies, there is little evidence or guidance in the literature regarding the construction of integrated case studies. The investigators wished to develop a suitable framework model in order to create an integrated pharmacy case study, and we selected warfarin to be the exemplar. The case study aims to move students towards application and critical analysis of scientific concepts that underpin safe and effective pharmacy practice. The purpose of this study was to examine the effectiveness of an integrated science and pharmacy practice case study on warfarin. Two research questions informed the study in relation to developing a suitable framework for generating integrated pharmacy case studies and the student experience when using an integrated pharmacy case study in a classroom setting.

\section{METHODS}

Following an in-depth analysis of previous case studies, common features were identified and categorized into five stages for creating an effective case study as discussed below (Figure 1). ${ }^{12,17,18}$

The first stage in developing an effective case study involves choosing a pharmacy-related setting. Generally, contextualized case studies in pharmacy education are set within a pharmacy workplace. We chose a community pharmacy as the setting for this case study.

The second stage is creating a fictional patient. Fictional patients are commonly used as a platform to illustrate the science and pharmacy practice of a medicine. This is normally done by creating a narrative involving a patient, stating the condition, and indicating the medicine treatment used. The fictional patient used in the case study detailed here is male, 62 years old, and receiving warfarin therapy for deep vein thrombosis (DVT). Other factors beyond the medication involved may be significant in the therapeutic outcome, eg, lifestyle factors, which are discussed under other relevant information.

The problem or dilemma presented in case studies usually involves destabilization of the patient's drug therapy. This supports the development of pharmacy students' higher-order thinking as the context requires

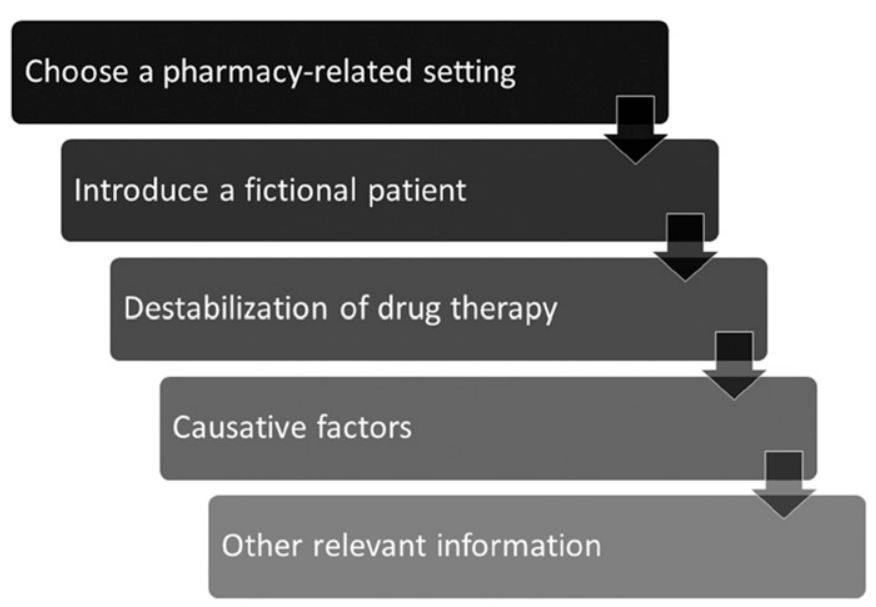

Figure 1. Framework for an Integrated Pharmacy Case Study 


\section{American Journal of Pharmaceutical Education 2019; 83 (5) Article 6688.}

analysis and evaluation rather than simple recollection of facts. As warfarin is the chosen therapy in this case study, the problem selected for the patient was hemorrhage. Hemorrhage, more commonly known as bleeding is the main adverse effect of warfarin. From a meta-analysis of 33 studies, major and fatal bleeding events occur respectively at rates of 7.2 and 1.3 per 100 patient-years. ${ }^{19}$

The fourth stage in creating the case study was to decide what the causative factors would be. In order to demonstrate the role of the pharmacist in reporting warfarin's main adverse drug reactions (ADRs), we needed to include some causative factors for the patient's bleeding to have occurred. These causative factors would then be used to demonstrate how the application of science underpins effective pharmacy practice.

Warfarin is metabolized by the cytochrome P450 (CYP) enzyme system. ${ }^{20}$ The pharmacist must therefore ensure if a patient were to take another medication, it would not inhibit or induce the CYP enzymes. If the CYP enzymes were induced or inhibited by another medication, warfarin's metabolism would be significantly affected. ${ }^{20}$

The fictional patient in this case study explains to the pharmacist that he started antibiotic treatment with metronidazole two days before coming into the community pharmacy. Metronidazole inhibits the CYP enzyme system, reducing warfarin's metabolism in the body. ${ }^{21}$ This enhances the anticoagulant effect of warfarin, which led to the patient's uncontrolled warfarin therapy and, consequently, hemorrhaging.

The causative factor presented here is the interaction of the antibiotic metronidazole with warfarin. Without an understanding of the science of warfarin, specifically its metabolism in the body and the enzyme systems involved, a pharmacist cannot analyse and comprehend the patient safety implications.

The fifth stage in developing the case study was inclusion of other relevant information. Details regarding changes to the patient's living arrangements and diet were clarified. However, it was also important to consider the extent of additional information included. The resulting cognitive overload caused by the "noise" of additional information in the case study could have negatively affected field dependent learners. ${ }^{2}$

Guided by this framework, we developed the case study focusing on warfarin therapy (Figure 1). Once the first draft of the integrated case study was completed, a professor of pharmaceutical chemistry and a professional lead instructor in clinical pharmacy reviewed it. The integrated case study was then piloted with final year MPharm students to assess its difficulty and ensure undergraduate students could understand it clearly. Their

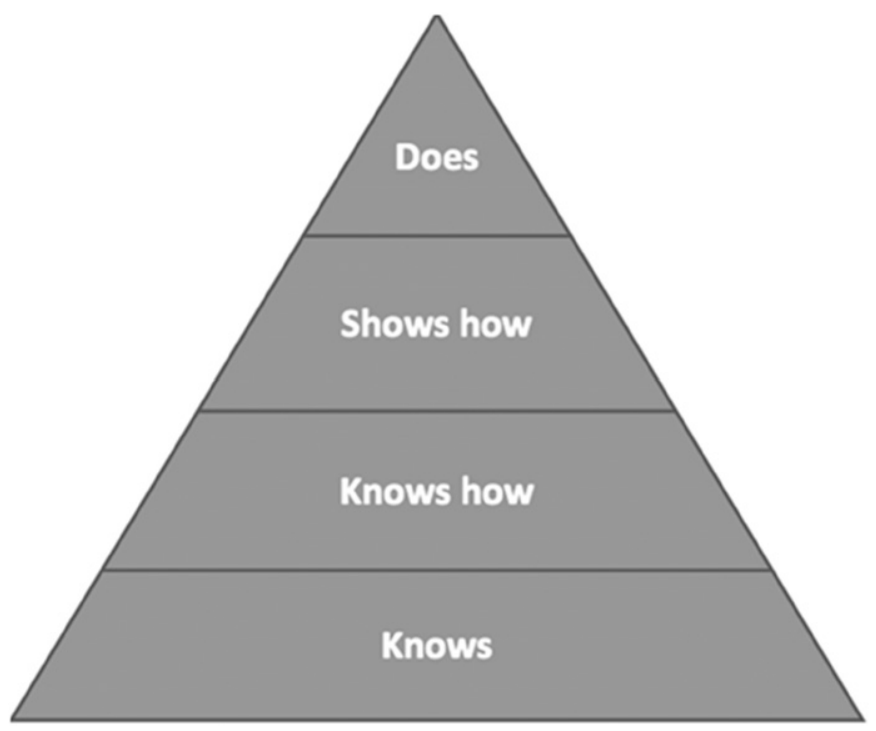

Figure 2. Framework for Clinical Assessment ${ }^{23}$

feedback indicated that the case study did not clarify whether the patient was on any other medication. As a result, the case study was reworded to clarify that the patient was not taking any other medication except metronidazole.

The integrated warfarin case study was presented to approximately 165 third-year MPharm students in a one-hour workshop as part of the Drug Discovery and Development module. Third-year students had covered the fundamental scientific and pharmaceutical principles related to warfarin in previous years, and this knowledge base would enable them to evaluate the effectiveness of an integrated case study comparing this strategy to their other learning approaches.

The outcome levels for the case study and associated questions were derived from Miller's competence and assessment hierarchy (Figure 2) and Bloom's taxonomy. ${ }^{23,24}$ Miller's pyramid illustrates the assessment of clinical skills and competence where each underlying level is the building block for the next level. We expect students to demonstrate not only that they "know" the theory that underpins clinical practice, but that they "know how" to apply this knowledge and "show how" that they can translate this learning to a suitable context.

The overall learning goal for the integrated warfarin case study was for students to apply basic scientific principles and determine how each causative factor could have led to the patient's hemorrhaging. A three-step, progressive question model (Figure 3) was adopted to scaffold the assessment design and support the students in meeting this learning goal. Part A of each question required students to revisit a familiar scientific concept. Part $B$ required students to understand and relate the scientific concept from part A to pharmacy practice (ie, the "know 


\section{American Journal of Pharmaceutical Education 2019; 83 (5) Article 6688.}

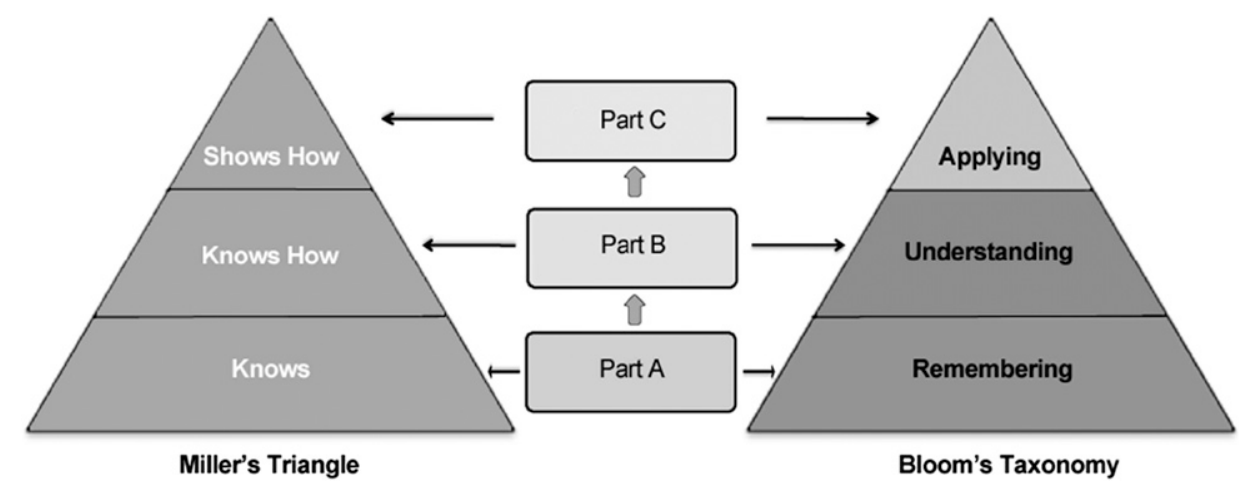

Figure 3. Three-step Progressive Assessment Model Based on Miller's Triangle and Bloom's Taxonomy

how" stage on Miller's Triangle). Part C further explored how both answers apply to the case study patient, and to "show how" they would use this information in a simulated environment.

Students were required to attend one workshop session altogether. Ideally, we hoped to have the cohort split into smaller, separate groups to encourage collaborative group discussions. However, the resources to do this were not available. The academic instructor presented students with the integrated case study questions sequentially during the workshop and then allowed time for small group discussions.

The learning outcomes for the integrated case study were aligned with the GPhC Standard 10 outcomes
"Future pharmacists: Standards for the initial education and training of pharmacists." ${ }^{2}$ How each question met the expectations of an MPharm student and also a preregistration pharmacist is shown in Table 1.

Ethical considerations with support from the MPharm Program Lead were conducted under University of Hertfordshire Ethical Guidelines. All student data sources were anonymized and the confidentiality of participants was ensured throughout dissemination of the research data.

Prior to the workshop, students were required to prepare responses to three background questions. These were: "Explain INR." "What is the main adverse effect of warfarin?" and "Why does warfarin interact with so many

Table 1. Expected Learning Outcomes Using an Integrated Warfarin Case Study and the Professional Expectations of a Pharmacist

\begin{tabular}{|c|c|c|}
\hline Outcomes & MPharm Level & Preregistration Level \\
\hline $\begin{array}{l}\text { Demonstrate how the science of pharmacy is applied in the design and } \\
\text { development of medicines and devices }\end{array}$ & Shows how & Knows how \\
\hline Respond appropriately to medical emergencies, including provision of first aid & Knows how & Shows how \\
\hline $\begin{array}{l}\text { Collaborate with patients, the public and other health care professionals to } \\
\text { improve patient outcomes }\end{array}$ & Knows how & Shows how \\
\hline $\begin{array}{l}\text { Identify inappropriate health behaviours and recommend suitable approaches } \\
\text { to interventions }\end{array}$ & Shows how & Does \\
\hline Instruct patients in the safe and effective use of their medicines and devices & Shows how & Does \\
\hline $\begin{array}{l}\text { Provide, monitor and modify prescribed treatment to maximize health } \\
\text { outcomes }\end{array}$ & Shows how & Does \\
\hline Communicate with patients about their prescribed treatment & Shows how & Does \\
\hline Record, maintain and store patient data & Shows how & Does \\
\hline $\begin{array}{l}\text { Establish and maintain patient relationships while identifying patients' desired } \\
\text { health outcomes and priorities }\end{array}$ & Shows how & Does \\
\hline Obtain and record relevant patient medical, social and family history & Shows how & Does \\
\hline $\begin{array}{l}\text { Communicate information about available options in a way which promotes } \\
\text { health understanding }\end{array}$ & Shows how & Does \\
\hline Conclude consultation to ensure a satisfactory outcome & Shows how & Does \\
\hline $\begin{array}{l}\text { Demonstrate the characteristics of a prospective professional pharmacist as set } \\
\text { out in relevant codes of conduct and behaviour }\end{array}$ & Does & Does \\
\hline
\end{tabular}




\section{American Journal of Pharmaceutical Education 2019; 83 (5) Article 6688.}

drugs?" Questions 1 and 2 provided students with the necessary background information needed for the workshop session, and question 3 encouraged initial thinking about the pharmaceutical science of warfarin covered in the case study. Students were required to answer five additional questions during the session (Appendix 1).

To evaluate student perceptions of this integrated case study instructional design, an online questionnaire and student focus groups were employed. The questionnaire consisted of 14 statements using a four-point Likert scale (Appendix 2) and was piloted with a focus group of fourth-year MPharm students.

The questionnaire was administered using an online survey tool (Survey Monkey, San Mateo, CA). Students from the third year were emailed individually, data were collected over a three-week period, and reminder emails were sent every week.

Two focus groups ( $\mathrm{n}=8$ students) were also conducted to obtain further insights into student attitudes and perceptions. An invitation was sent by email to all thirdyear students asking for voluntary participation.

\section{RESULTS}

The students correctly answered the three background questions and were discussed at the beginning of the workshop. The students worked collaboratively during the workshop to answer the questions in Appendix 1.

Two focus groups ( $n=8$ students) were conducted. One focus group consisted of three students (all female) and the second had five students (two male and three female). In the pilot focus group, students reported increased engagement and improved learning occurred when they enjoyed what was being taught; therefore, a further question on this aspect was included in the final online questionnaire. There was a $44 \%$ response rate $(n=72)$ to the online questionnaire. All respondents indicated their age was from 18 to 24 years; $21 \%$ were male and $79 \%$ were female.

From the online questionnaire, there was complete agreement (no student disagreed) that the case study integrated the science of warfarin to pharmacy practice, all students agreed that they enjoyed the case study approach, and $94 \%$ agreed that this approach helped them to understand the science of warfarin more than if delivered through a traditional lecture. "It was great because we were able to discuss it instead of researching answers so a better understanding was gained. Also, the style of teaching allows participation rather in a lecture" and "I really enjoyed the workshop. It was much more interesting than most lectures." There was a mixed response on the structure delivery of the workshop to smaller groups or to the entire cohort. A small number of students re- ported that the workshop format did not allow complete participation. Student perspectives on the integrated warfarin case study obtained from the online questionnaire are shown in Table 2.

The majority of student feedback from the questionnaire and focus groups was that more time should have been given to complete the case study. Almost two-thirds $(62.5 \%)$ of students strongly agreed and $35.9 \%$ agreed that the MPharm degree program should introduce more case studies that incorporate science and pharmacy practice into the curriculum.

\section{DISCUSSION}

We developed a suitable framework to support the design and structure of an integrated pharmacy case study and assessed the implementation of an integrated case study on warfarin therapy within the third year of an MPharm degree program. Using such a contextualized approach helps students to link their learning experience to real world scenarios, which has been shown to increase motivation. ${ }^{16}$ The integration of science and pharmacy practice facilitates students to gain a deeper appreciation of the different disciplines within pharmacy and, more specifically, a greater understanding of how they link together towards the development of therapeutics. When we reviewed the literature for examples of case studies that integrated science and chemistry of a medicine to pharmacy practice suitable for undergraduate students, the extent of appropriate examples were limited. This identified the need for a suitable framework that could be used to shape and guide the development of an integrated pharmacy case study. The framework we have created may be adopted by other schools, and the exercise using the warfarin case study may be used as presented or amended to complement their pharmacy curricula.

Warfarin therapy was chosen as a central therapeutic area because of its prevalence in pharmacy practice and the importance for pharmacy students to understand the CYP enzymes systems and associated pharmacokinetics. Warfarin is metabolized primarily via oxidation in the liver by CYP2C9. Polymorphism in the CYP family and particularly CYP2D6, 2C19, and 2C9 polymorphisms account for the most frequent variations in phase 1 metabolism of drugs as these specific enzymes are involved in the metabolism of up to $80 \%$ of drugs used today. ${ }^{25}$ It is critical that pharmacy students understand the implications of polymorphism, the large inter-individual variability in drug clearance, half-life, and adverse drug reactions and responses in clinical practice. Creating suitable learning activities that allow students to revisit important concepts throughout the entire curriculum, 


\section{American Journal of Pharmaceutical Education 2019; 83 (5) Article 6688.}

Table 2. Results of an Online Questionnaire with Student Evaluations on the Integrated Warfarin Case Study

\begin{tabular}{|c|c|c|c|c|c|}
\hline Question & \#Responses & $\begin{array}{l}\text { Strongly } \\
\text { Agree } \\
(\%)\end{array}$ & $\begin{array}{c}\text { Agree } \\
(\%)\end{array}$ & $\begin{array}{l}\text { Disagree } \\
\quad(\%)\end{array}$ & $\begin{array}{l}\text { Strongly } \\
\text { Disagree } \\
\quad(\%)\end{array}$ \\
\hline $\begin{array}{l}\text { The case study approach helped me to understand the science } \\
\text { more than if it were a traditional lecture. }\end{array}$ & 66 & 40.6 & 53.1 & 6.3 & 0 \\
\hline $\begin{array}{l}\text { The questions that were asked addressed the GPhC learning } \\
\text { outcomes mentioned at the beginning of the case study. }\end{array}$ & 65 & 26.6 & 73.4 & 0 & 0 \\
\hline $\begin{array}{l}\text { The learning outcomes at the beginning were useful } \\
\text { and necessary. }\end{array}$ & 65 & 31.3 & 65.6 & 3.1 & 0 \\
\hline $\begin{array}{l}\text { The table at the end is a useful summary tool that could be } \\
\text { used for drugs other than warfarin. }\end{array}$ & 64 & 43.8 & 56.2 & 0 & 0 \\
\hline $\begin{array}{l}\text { I would have preferred the workshop to be in groups rather } \\
\text { than as the whole year. }\end{array}$ & 64 & 26.6 & 26.6 & 40.6 & 6.2 \\
\hline $\begin{array}{l}\text { The link between the science and pharmacy practice of } \\
\text { warfarin was not clear. }\end{array}$ & 64 & 0 & 3.1 & 64.1 & 32.8 \\
\hline The time allowed for the workshop was sufficient. & 64 & 6.3 & 39.1 & 43.8 & 10.8 \\
\hline $\begin{array}{l}\text { The MPharm degree program should introduce more case } \\
\text { studies that incorporate science and pharmacy practice into } \\
\text { the curriculum. }\end{array}$ & 64 & 62.5 & 35.9 & 1.6 & 0 \\
\hline
\end{tabular}

increasing the complexity with each visit, is a strategy advocated for the design of a spiral curriculum that allows the situation of a new learning experience within the context of a previous learning experience. ${ }^{26}$

All students agreed that they enjoyed the case study approach, and 94\% agreed that this approach helped them to understand the science of warfarin more than if delivered through a traditional lecture. This active learning approach supports student engagement. A study on the effect of integrated teaching with case-based learning (CBL) for biochemistry in an undergraduate medical program found that the performance of students in terms of clinical knowledge on an innovative CBL curriculum significantly improved $(p<.001)$ compared to a more traditional, lecture-based curriculum. ${ }^{27}$ Similar to our integrated case study approach, there was much positive student feedback related to the valuable exchange of ideas in the CBL approach, and the majority of students considered their understanding of the subject to be better and helpful in terms of their future application of knowledge.

The inclusion of learning objectives in the case study was highlighted as positive for learning. "It was very good that the questions in the case study were linked to learning objectives. So not only do we know what we're learning, but also how to apply that knowledge and then know what's required of us." There were mixed views on the delivery format of the workshop to smaller groups or to the entire cohort. We had identified the benefit of smaller groups for increased interactivity, but because of practical constraints, we were unable to achieve this. Student comments included, "It was a good learning experience but would have loved to be in smaller groups." Interesting insights into student perceptions of smaller groups sizes and missing key discussion points in different groups were highlighted in the student evaluations. Some students feel inhibited to speak up in a large group and smaller groups would provide a safer learning environment. There were also concerns from some students about missing discussion points from other smaller workshops and how everyone in a lecture hears the same consistent message.

The time allocated to the workshop was also a concern in the planning phase. We were not surprised that the majority of student feedback indicated that more time should have been available. "I think there wasn't enough time to go through all the questions. Even though we did get the answers put up on the site later you still don't get the same level of comprehension as you would have if we'd been able to go through all the questions in the workshop." 


\section{American Journal of Pharmaceutical Education 2019; 83 (5) Article 6688.}

Almost two-thirds (62.5\%) of the students strongly agreed that the MPharm degree program should introduce more case studies that incorporate science and pharmacy practice into the curriculum. Student feedback also supported this strategy: "these kind of case studies should more appear during MPharm course. Students must have the chance to discuss and learn about different case studies about a range of illnesses and conditions."

The three-step integrated model was a successful scaffolding approach to support the integration of science and pharmacy practice and made explicit links between the fundamental science and clinical aspects for students. One student said, "It was interesting to see the link between why a patient might get side effects or other disorders as a result of warfarin explained through the science of how it works rather than just listing side effects." Another stated that "because the structure of Vitamin K is similar to warfarin, but you didn't know the drug was warfarin, you could figure out how it works." The three-step integrated model used can be incorporated to support teaching activities for other clinical drugs.

The instructors involved in the development of the integrated model considered it extremely useful in terms of the contextualisation of chemistry and pharmacology into a clinical situation. A limitation of this report is that the model has been developed in a single institution with a relatively small cohort of students. The evaluations include the student perceptions using this approach in a teaching session and future work is needed to fully analyse the impact of an integrated case study approach on student learning outcomes.

The potential future application of the framework could provide a student-centered approach for final year MPharm students to create and develop their own case studies.

We believe the framework provided here further supports an independent, deep-learning approach that enables pharmacy students to stretch their application of concepts, implementing their own case study design, considering key components outlined in the framework.

\section{CONCLUSION}

A framework to support the integration of science, pharmacology, and pharmacy practice was developed and used to successfully design and implement an integrated case study focusing on warfarin therapy. Pharmacy students found the activity enjoyable and felt that this approach better supported their learning. Other pharmacy educators should consider using this approach of integrating case studies within clinical pharmacy education to help contextualize pharmaceutical chemistry and pharmacology.

\section{REFERENCES}

1. Holbrook AM, Pereira JA, Labiris R, et al. Systematic overview of warfarin and its drug and food interactions. Archives of Internal Medicine. 2005;165(10):1095-1106.

2. General Pharmaceutical Council. Future pharmacists: standards for the initial education and training of pharmacists. 2011; https:// www.pharmacyregulation.org/education/education-standards.

Accessed June 6, 2017.

3. Center for the Advancement of Pharmacy Education. CAPE Educational Outcomes. 2013; http://www.aacp.org/ resources/education/cape/Pages/default.aspx. Accessed June 6, 2017.

4. Accreditation Council for Pharmacy Education. Accreditation Standards and Key Elements for the Professional Program in Pharmacy leading to the Doctor of Pharmacy Degree. 2015; https:// www.acpe-accredit.org/pdf/Standards2016FINAL.pdf. Accessed June 6, 2017.

5. Ratka A. Integration as a paramount educational strategy in academic pharmacy. Am J Pharm Educ. 2012;76(2):Article 19. 6. Pearson M, Hubball H. Curricular integration in pharmacy education. Am J Pharm Educ. 2012;76(10):Article 204.

7. Harden RM. The integration ladder: a tool for curriculum planning and evaluation. Med Educ. 2000;34(7):551-557.

8. Marriott J, Styles K, McDowell J. The Pharmville community: a curriculum resource platform integrating context and theory. Am J Pharm Educ. 2012;76(9):Article 178.

9. Kullgren J, Radhakrishnan R, Unni E, Hanson E. An integrated course in pain management and palliative care bridging the basic sciences and pharmacy practice. Am J Pharm Educ. 2013; 77(6):Article 121.

10. Nelson M, Dean Allison S, McCollum M, et al. The Regis Model for pharmacy education: a highly integrated curriculum delivered by Team-Based Learning (TBL). Curr Pharm Teach Learn. 2013;5:555563.

11. Richardson A, Curtis ADM, Moss GP, et al. Simulated drug discovery process to conduct a synoptic assessment of pharmacy students. Am J Pharm Educ. 2014;78(2):Article 41.

12. Marshall LL, Nykamp D. Active-learning assignments to integrate basic science and clinical course material. Am J Pharm Educ. 2010;24(7):Article 119.

13. Pierce R, Fox J. Vodcasts and active-learning exercises in a "flipped classroom" model of a renal pharmacotherapy module. Am J Pharm Educ. 2012;76(10):Article 196.

14. Ives TJ, Deloatch KH, Ishaq KS. Integration of medicinal chemistry and pharmacotherapeutics courses: a case-based, learnercentered approach. Am J Pharm Educ. 1998;62:406-411.

15. Lohman, M. Cultivating problem-solving skills through problem-based approaches to professional development. Human Resource Development Quarterly. 2002;13(3):243-261.

16. Bennett J, Lubben F, Hogarth S. Bringing science to life: a synthesis of the research evidence on the effects of context-based and STS approaches to science teaching. Science Education. 2007;91:347-370.

17. Currie BL, Chapman RL, Christoff JJ, Sikorski L. Patient related case studies in medicinal chemistry. Am J Pharm Educ. 1994;58:446450 . 


\section{American Journal of Pharmaceutical Education 2019; 83 (5) Article 6688.}

18. Roche VF. Antihyperlipidemic statins: a self-contained, clinically relevant medicinal chemistry lesson. Am J Pharm Educ. 2005;69(4):Article 77.

19. Linkins L, Choi P, Douketis J. Clinical impact of bleeding in patients taking oral anticoagulant therapy for venous thromboembolism. Ann Intern Med. 2013;139:893-900.

20. Palkimas Jr MP, Skinner HM, Gandhi PJ, Gardner AJ. Polymorphism induced sensitivity to warfarin: a review of the literature. J Thrombosis Thrombolysis. 2003;15(3):

205-212.

21. Baxter K, ed. Stockley's Drug Interactions: A Source Book of Interactions, Their Mechanisms, Clinical Importance and Management. London: Pharmaceutical Press; 2010:438-439.

22. Johnstone AH, Al-Naeme FF. Room for scientific thought? Int $J$ Sci Educ. 1991;13:187-192.
23. Miller GE. The assessment of clinical skills/competence/ performance. Acad Med. 1990;65(9):563-567.

24. Krathwohl DR. A revision of Bloom's taxonomy: an overview. Theory into Practice. 2002;41(4):212-218.

25. Zhou SF, Liu JP, Chowbay B. Polymorphism of human cytochrome P450 enzymes and its clinical impact. Drug Metabolism Reviews. 2009;41(2):89-295.

26. Harden RM. What is a spiral curriculum? Medical Teacher. 1999;21(2):141-143.

27. Surapaneni KM. The effect of integrated teaching with case based learning (CBL) in the biochemistry of undergraduate medical curriculum. J Clin Diagn Res. 2010;5:3058-3063.

28. Francis SA, Smith F, Malkinson J, Constanti A, Taylor K. Integrated Pharmacy Case Studies. London: Pharmaceutical Press; 2015. 


\section{American Journal of Pharmaceutical Education 2019; 83 (5) Article 6688.}

\section{Appendix 1. Additional Questions on the Warfarin Case Study}

1. A. Vitamin $\mathrm{K}$ is required for the blood to clot. Considering the structures of both warfarin and Vitamin K, what could you suggest as the mechanism of action for warfarin?

B. Therefore, describe how Vitamin $\mathrm{K}$ would affect anticoagulation therapy with warfarin

C. i) Considering your answers to $1 \mathrm{~A}$ and $1 \mathrm{~B}$, describe what you think could have contributed to Patient AB's "uncontrolled anticoagulation therapy"

ii) What would you advise him based on the above information?

2. A. i) Warfarin is administered as sodium salt. Why is this important for oral absorption?

ii) How is salt formation possible when no carboxylic acid functional group is present in warfarin?

B. Once a tablet is taken and absorbed, how is the effect of warfarin monitored?

C. i) How is a Pharmacist involved in the monitoring of warfarin for a patient?

ii) Considering your answer to $2 \mathrm{Ci}$ ), what advice would you give to Patient $\mathrm{AB}$ ?

3. A. Warfarin is administered as a racemate drug. Explain from its chemical structure how warfarin is a racemate.

B. The two enantiomers that make up the warfarin racemate are both metabolized by the Cytochrome P450 (CYP) enzyme system. By knowing the enzyme system involved in the metabolism of warfarin, what must a Pharmacist ensure if a patient needs to take another medication?

C. i) Considering your answers to $3 \mathrm{~A}$ and $3 \mathrm{~B}$, what does this indicate about warfarin?

ii) Therefore, explain the reason for Patient AB's "uncontrolled anticoagulation therapy" and symptoms.

4. A. i) $S$-warfarin and $R$-warfarin have the same molecular formula but differ in the spatial arrangements of their functional groups. Would you expect them both to have the same pharmacodynamic activities and pharmacokinetic properties?

ii) Explain why.

B. Some drugs can interact stereo-specifically with warfarin. When a drug interacts with $R$-warfarin, it would cause a minor increase in the anticoagulant effect of warfarin. However, when a drug interacts with $S$-warfarin, it would cause a major increase in anticoagulant effect of warfarin. What does this suggest about $S$-warfarin compared to $R$-warfarin?

C. Considering your answers to $4 \mathrm{~A}$ and $4 \mathrm{~B}$, and the alarming symptoms Patient $\mathrm{AB}$ is experiencing, what does this tell you about the interaction between Metronidazole and warfarin?

5. A. By summarising all of the above, what advice would you give Patient AB?

B. How could you ensure patient safety for $A B$ in the future?

C. As a quick summary, complete the table below for each scientific concept involved in this case study.

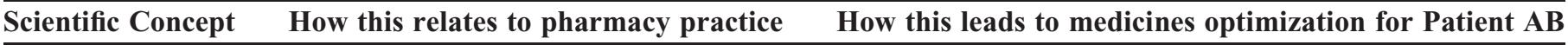




\section{American Journal of Pharmaceutical Education 2019; 83 (5) Article 6688.}

Appendix 2. Questionnaire

Please indicate your age group: $18-24 \_25-34 \_35-44 \_45$ or over

Please indicate your gender: Male __ Female

Strongly Strongly

Statement

Agree

Agree Disagree

Disagree

I enjoyed the case study approach used in the workshop.

The case study approach helped me to understand the science more than if it were a traditional lecture.

The questions that were asked addressed the learning outcomes discussed at the beginning of the case study.

The case study integrated the science of warfarin and how this links to pharmacy practice.

The learning outcomes at the beginning of the workshop were useful and necessary.

The table at the end is a useful summary tool that could be used for drugs other than warfarin.

I would have preferred to prepare all the questions prior to the workshop and work through them together with the lecturer.

I would have preferred the workshop to be in groups rather than as the whole year.

The link between the science and pharmacy practice of warfarin was not clear.

The time allowed for the workshop was sufficient.

The MPharm degree program should introduce more case studies that incorporate science and pharmacy practice into the curriculum.

Please state (if not already) your overall opinion of the case study workshop, including any comments, concerns, particular strengths or weaknesses. 